\title{
Article \\ Role of Decorin in Posterior Capsule Opacification and Eye Lens Development
}

\author{
Shinsuke Shibata ${ }^{1}$, Naoko Shibata ${ }^{1}$, Satoshi Ohtsuka ${ }^{2,3}$, Yasuo Yoshitomi ${ }^{4}{ }^{(D)}$, Etsuko Kiyokawa ${ }^{5}{ }^{(0)}$, \\ Hideto Yonekura ${ }^{4}$, Dhirendra P. Singh ${ }^{6}$, Hiroshi Sasaki ${ }^{1}$ and Eri Kubo ${ }^{1, * \mathbb{D}}$ \\ 1 Department of Ophthalmology, Kanazawa Medical University, Ishikawa 9200293, Japan; \\ shinsuke.shiba@gmail.com (S.S.); n-shiba@kanazawa-med.ac.jp (N.S.); mogu@kanazawa-med.ac.jp (H.S.) \\ 2 Medical Research Institute, Kanazawa Medical University, Ishikawa 9200293, Japan; \\ sohtsuka@koto.kpu-m.ac.jp \\ 3 Laboratory for Experimental Animals, Kyoto Prefectural University of Medicine, Kyoto 6028566, Japan \\ 4 Department of Biochemistry, Kanazawa Medical University, Ishikawa 9200293, Japan; \\ yositomi@kanazawa-med.ac.jp (Y.Y.); yonekura@kanazawa-med.ac.jp (H.Y.) \\ 5 Department of Oncogenic Pathology, Kanazawa Medical University, Ishikawa 9200293, Japan; \\ kiyokawa@kanazawa-med.ac.jp \\ 6 Department of Ophthalmology, University of Nebraska Medical Center, Omaha, NE 68198, USA; \\ dpsingh@unmc.edu \\ * Correspondence: kuboe@kanazawa-med.ac.jp; Tel.: +81-76-286-2211
}

check for updates

Citation: Shibata, S.; Shibata, N.; Ohtsuka, S.; Yoshitomi, Y.; Kiyokawa, E.; Yonekura, H.; Singh, D.P.; Sasaki, H.; Kubo, E. Role of Decorin in Posterior Capsule Opacification and Eye Lens Development. Cells 2021, 10, 863. https://doi.org/10.3390/ cells10040863

Academic Editor: Alexander E. Kalyuzhny

Received: 25 February 2021

Accepted: 8 April 2021

Published: 9 April 2021

Publisher's Note: MDPI stays neutral with regard to jurisdictional claims in published maps and institutional affiliations.

Copyright: (c) 2021 by the authors. Licensee MDPI, Basel, Switzerland. This article is an open access article distributed under the terms and conditions of the Creative Commons Attribution (CC BY) license (https:/ / creativecommons.org/licenses/by/ $4.0 /)$.

\begin{abstract}
Decorin (DCN) is involved in a variety of physiological and pathological processes. Epithelial-mesenchymal transition (EMT) of lens epithelial cells (LECs) has been proposed as a major cause for the development of posterior capsule opacification (PCO) after cataract surgery. We investigated the plausible target gene(s) that suppress PCO. The expression of Dcn was significantly upregulated in rat PCO tissues compared to that observed in the control using a microarray-based approach. LECs treated with fibroblast growth factor (FGF) 2 displayed an enhanced level of DCN expression, while LECs treated with transforming growth factor (TGF) $\beta-2$ showed a decrease in DCN expression. The expression of tropomyosin 1 (Tpm1), a marker of lens EMT increased after the addition of TGF $\beta$-2 in human LEC; however, upregulation of Tpm 1 mRNA or protein expression was reduced in human LECs overexpressing human DCN (hDCN). No phenotypic changes were observed in the lenses of 8- and 48-week-old transgenic mice for lens-specific hDCN $(h D C N-T g)$. Injury-induced EMT of the mouse lens, and the expression patterns of $\alpha$ smooth muscle actin, were attenuated in $h D C N-T g$ mice lenses. Overexpression of DCN inhibited the TGF $\beta$-2-induced upregulation of Tpm1 and EMT observed during wound healing of the lens, but it did not affect mouse lens morphology until 48 weeks of age. Our findings demonstrate that DCN plays a significant role in regulating EMT formation of LECs and PCO, and suggest that for therapeutic intervention, maintenance of physiological expression of DCN is essential to attenuate EMT progression and PCO formation.
\end{abstract}

Keywords: Decorin; posterior capsule opacification; epithelial-mesenchymal transition; lens development; wound healing

\section{Introduction}

According to the latest report of the World Health Organization (WHO), cataract is the primary cause of blindness in the world, which affected 20 million people in 2010 (WHO. Global data on visual impairments 2010. WHO/NMH/PBD/12.01). Although cataracts can be cured surgically, the process may be difficult to perform even in many developing countries [1]. In addition, after cataract surgery, aberrant cell proliferation, fibrosis, and lens regeneration under the lens capsule lead to fibroblastic opacification and secondary visual impairment, known as the posterior capsule opacification (PCO) or after-cataracts. Currently, Nd-YAG laser posterior capsulotomy is the only treatment for PCO. However, 
after this laser treatment, postoperative uveitis, cystoid macular edema, transient increase in intraocular pressure, retinal detachment, and intraocular lens damage may occur as complications. In addition, Nd-YAG laser capsulotomy is occasionally unavailable in developing countries, leading to surgery-associated blindness. Furthermore, early cataract surgery and refractive correction are necessary to prevent amblyopia in cases of pediatric cataracts [2]. However, visually significant PCO hinders visual rehabilitation, increasing the probability of deprivation amblyopia after pediatric cataract surgery. PCO develops in $100 \%$ of eyes under 4 years of age if the posterior capsule of the lens remains intact [3]. Thus, secondary surgery for capsulotomy is occasionally required in younger children using general anesthesia [3]. Furthermore, epithelial-mesenchymal transition (EMT) and PCO should be regulated during re-growth of lens epithelial cells (LECs) for clinical treatments using accommodative lens refilling [4] and for the regeneration of clear crystalline lens in human eyes after cataract surgery.

Transforming growth factor (TGF) $\beta$ signaling plays a significant role in the pathobiology of human anterior subcapsular cataract [5-8] and PCO [1,7,9,10]. In addition, TGF $\beta$ induces tissue fibrosis, EMT, and apoptosis [11-14] by upregulating genes encoding $\alpha$-smooth muscle actin ( $\alpha$ SMA), collagen types I and III, and tropomyosin (Tpm). Previous studies have revealed that fibroblast growth factor (FGF) is also involved in the stimulation of lens fiber differentiation $[15,16]$ and mitosis, increasing the formation of collagen in PCO [17]. In our previous study, we observed that Tpm 1 and 2 are involved in regulating and stabilizing actin microfilaments and are induced by TGF $\beta-2$ during EMT in LECs. Importantly, we found that FGF2 acts as an antagonist of TGF $\beta$-mediated EMT progression [12]. Furthermore, we demonstrated that the expression of rat tropomyosin and human TPM1 and TPM2 was highly elevated in a rodent model of PCO and human cataractous lens capsules with LECs, suggesting their association with EMT and lens regeneration during PCO progression [18]. However, the molecular mechanisms underlying the progression and inhibition of PCO have not yet been clarified.

In this study, we aimed to analyze the changes in gene expression patterns during rat and mouse PCO formation in vivo using a microarray-based approach and real-time quantitative polymerase chain reaction (RT-qPCR). Furthermore, we analyzed the role of Decorin $(D C N)$, the level of which increased markedly in rat PCO tissues, and during EMT and lens development. To achieve the impact of $D C N$ expression on eye lens in vivo, we generated lens-specific human $D C N$ transgenic mouse $(h D C N-T g)$. In addition, to establish a correlation between results obtained in vitro and $h D C N-T g$ in vivo, we assessed the levels of human DCN protein and mRNA in human aqueous humor and LECs of cataractous patients. We first found that abundant expression of Dcn is involved in EMT and that may result in PCO formation. Thus, the results of the study increase our understanding of the role of Dcn in EMT and PCO formation and plausible the related molecular mechanism underlying its effects.

\section{Materials and Methods}

\subsection{Animals}

All animal experiments were approved by the Kanazawa Medical University Ethics Committee for Animal Experiments (authorization No. 2018-3) and were conducted in accordance with the National Institutes of Health Guide for the Care and Use of Laboratory Animals and the Institutional Guidelines for Laboratory Animals from the Kanazawa Medical University. Sprague-Dawley (SD) rats, and C57BL/6J, C57BL/6JJmsSlc, and Slc:ICR mice were purchased from Sankyo Laboratories Japan (Ishikawa, Japan).

\subsection{Surgical Procedure for Generation of PCO Animal Model}

Method for extracapsular clear lens extraction (ECLE) from rat and mouse eyes was established, confirming the histological observation of rat PCO in our previous study [19]. Eighteen 7-week-old female albino SD rats and twelve 7-week-old C57BL/6J mice were used as PCO animal models. ECLE was performed in both eyes of all rats and mice 
anesthetized with intraperitoneal administration of a combination anesthetic prepared with $0.3 \mathrm{mg} / \mathrm{kg}$ body weight medetomidine, $4.0 \mathrm{mg} / \mathrm{kg}$ body weight midazolam, and $5.0 \mathrm{mg} / \mathrm{kg}$ body weight butorphanol (Wako, Osaka, Japan). Animals were sacrificed at either 0 (after the surgery was completed) (day 0), 7 (1 week (W)), or 14 days ( $2 \mathrm{~W}$ ) after surgery by administering a lethal dose of $\mathrm{CO}_{2}$. Mice exhibited no signs of distress during euthanasia. Euthanasia by $\mathrm{CO}_{2}$ inhalation was performed according to the American Veterinary Medical Association (AVMA) Guidelines for the Euthanasia of Animals. Lens capsules with LECs removed from all eyes were used as PCO samples. All PCO samples from right eyes were processed for microarray studies ( $n=6$ at each time point) and all PCO samples from left eyes were used for reverse transcription-quantitative PCR (RT-qPCR) ( $n=4$ at each time point) and protein blotting ( $n=2$ at each time point).

\subsection{RNA Extraction}

Total RNAs from rat and mouse PCO, human LEC samples, cultured mouse LECs (MLEC), and Simian virus 40-transformed human LECs (SRA01/04) (SRA-HLECs) were extracted using the RNeasy micro kit (Qiagen Inc., Valencia, CA, USA) following the manufacturer's instructions. Samples of RNA were set aside for RT-qPCR to verify the results obtained from the microarray analysis. Total RNA quality was assessed by determining UV 260/280 absorbance ratios and examining RNA size distribution on NanoDrop ND-1000 (NanoDrop Technologies, Inc., Wilmington, DE, USA) processed on the Agilent 2100 Bioanalyzer (Agilent Technologies, Santa Clara, CA, USA) using the total RNA electrophoresis program. The purity and integrity of RNA were examined and validated as described previously [20]. The quality of total RNA was analyzed by evaluating the RNA integrity number (RIN) using Bioanalyzer RNA analysis (Agilent Technologies Japan Ltd., Tokyo, Japan). All RNA samples showed RIN > 9.0.

\subsection{Microarray and Gene Ontology Analysis}

Three rat PCO samples from each group on day $0,1 \mathrm{~W}$, and $2 \mathrm{~W}$ were used for microarray analysis to screen genes associated with rat PCO. All samples were processed for microarray analysis as follows: RNA labeling and hybridization were performed using GeneChip ${ }^{\circledR} 3^{\prime}$ IVT PLUS reagent kit (Affymetrix, Inc. Santa Clara, CA, USA) according to the manufacturer's protocol. Labeled cDNA was hybridized to Affymetrix ${ }^{\circledR}$ GeneChip ${ }^{\circledR}$ rat genome 2302.0 array (Affymetrix, Inc.) and scanned with a GeneChip ${ }^{\circledR}$ Scanner $30007 \mathrm{G}$ (Affymetrix, Inc.). The scanned images were analyzed with AGCC (Affymetrix ${ }^{\circledR}$ GeneChip ${ }^{\circledR}$ Command Console ${ }^{\circledR}$ Software (v.10.7.3.1)) and Affymetrix ${ }^{\circledR}$ Expression ComsoleTM (Affymetrix, Inc.).

Per chip normalization was performed by dividing each gene's value by the specific control values or by the average intensity in the single array. Normalized data were exported for subsequent analysis. Genes with normalized ratios more than 2.0-fold or less than 0.5 -fold were selected as significant genes.

\subsection{RT-qPCR Validation}

RT-qPCR was used to validate the significantly affected genes selected using microarray analysis and to analyze Dcn expression in mouse PCO samples and cultured MLECs and HLECs. To assess the expression of human DCN, rat and mouse Dcn, rat Tpm2, mouse and human Tpm1, and TGF $\beta$-induced (Tgfbi) mRNAs, we conducted relative quantification of mRNA using Prism7300 (Applied Biosystems ${ }^{\circledR}$, ThermoFisher Scientific Japan Ltd., Tokyo, Japan). Comparative Ct method was used for relative quantification of mRNA expression. PCR amplification was performed using a TaqMan universal master mix and pre-developed rat, mouse, and human Dcn (Hs00754870_s1, Cat\# 4331182), rat Tgfbi (Rn01442102_m1, Cat\# 4331182), rat Tpm2 (Rn01439798_g1, Cat\# 4351372), and mouse Tpm1 (Hs00165966_m1, Cat\# 4331182) and human Tpm1 (Hs04398572_m1, Cat\# 4331182) probe mix (Applied Biosystems ${ }^{\circledR}$ ). The relative quantity of each mRNA was determined using the comparative $\mathrm{Ct}$ method and then normalized using a pre-developed TaqMan 
$18 \mathrm{~S}$ ribosomal RNA (18s rRNA) VIC probe or glyceraldehyde-3-phosphate dehydrogenase $(\mathrm{GAPDH})$ as an endogenous control (Applied Biosystems ${ }^{\circledR}$ ).

\subsection{Construction of Green Fluorescent Protein (GFP)- $h D C N$ Vector and Lentivirus Production}

For generating cells (tissues) secreting $\mathrm{hDCN}$ protein in vitro, we used a lentivirus expression system (SBI System Biosciences, Palo Alto, CA, USA). Briefly, $h D C N$ was amplified by PCR using the following primers; forward primer $5^{\prime}$-tggatccgccgccaccatgaaggccactatcatcctc $-3^{\prime}$ and reverse primer $5^{\prime}$-agaattcttacttatagtttccgagttgaatgg- $3^{\prime}$. The fragment was sub-cloned into the pBRBlue vector and confirmed by sequencing. Then, the $h D C N$ fragment was excised using BamHI and EcoRI and sub-cloned in the pCDH1-EF1-copGFP (SBI) vector (pCDH-CMV- $h D C N$-EF1-copGFP) (SBI). Lentivirus particles were then produced in HEK293TN cells (System Biosciences) following transfection of pCDH-CMV- $h D C N-E F 1-$ copGFP vector with packaging vectors, psPAX2 and pMD2.G (deposited by Didier Trono, Lausanne, Switzerland: Addgene plasmid \#12260 and \#12259 respectively, Addgene, MA). Lentivirus particles were collected from the supernatants of $48 \mathrm{~h}$ culture media and concentrated with PEG-it solution (System Biosciences). Lentivirus infectious units (IFU) were determined by the serial dilution method to adjust copy numbers for each experiment.

\subsection{Cell Culture}

Primary cultured MLECs were generated from 6-week-old Balb/C mice $(n=8)$ as described previously [21]. MLECs were maintained in Dulbecco's modified Eagle's media (DMEM; Wako) with $10 \%$ fetal bovine serum (FBS; Sigma, St. Louis, MO, USA) at $37^{\circ} \mathrm{C}$ in a 19:1 air $/ \mathrm{CO}_{2}$ atmosphere as described previously [21]. Cells from passages 5-7 were used for the experiments. Human LECs (SRA01/04: SRA-HLECs) were kindly gifted by Dr. Nobuhiro Ibaraki (Ibaraki Eye Clinic, Tochigi, Japan). SRA-HLECs were cultured in DMEM supplemented with $20 \%$ FBS (Sigma) at $37^{\circ} \mathrm{C}$ in a 19:1 air $/ \mathrm{CO}_{2}$ atmosphere.

To assess the effects of FGF2 (PeproTech, RockyHill, NJ, USA) or TGF $\beta-2$ (R \& D Systems Inc., Minneapolis, MN, USA), MLECs or SRA-HLECs were plated in triplicate in 35-mm culture dishes (TPP ${ }^{\circledR}$ Techno Plastic Products AG, Trasadingen, Switzerland). Cells growing in DMEM containing $0.1 \%$ bovine serum albumin (BSA) (Wako) in the presence or absence of various test growth regulators received $0-100.0 \mathrm{ng} / \mathrm{mL}$ FGF2 or 0 to $10 \mathrm{ng} / \mathrm{mL}$ TGF $\beta-2$ every other day for up to four days.

To determine the effect of DCN overexpression, the pCDH-CMV- $h D C N$-EF1-copGFP lentivirus was used to generate eukaryotic cells overexpressing GFP in the cytoplasm, and secreting $h D C N$ into the medium. SRA-HLECs were cultured in DMEM supplemented with $20 \%$ FBS. For the negative control, the pCDH1-EF1-copGFP (SBI) lentivirus (GFP-Vec) was transduced into SRA-HLECs.

\subsection{Western Blotting}

Protein lysates of mouse PCO samples were prepared in ice-cold radioimmunoprecipitation assay (RIPA) buffer. Culture medium was collected and concentrated using Amicon ${ }^{\circledR}$ Ultra-0.5 centrifugal filters (Merck Millipore Ltd. County Cork, Ireland) after transduction of GFP-hDCN and GFP-Vec to confirm the secretion of hDCN from SRA-HLECs. For western blotting, the concentrated medium or protein samples were treated with $0.2 \mathrm{U} / \mathrm{mL}$ protease-free chondroitinase (CSase)-ABC (C-ABC) (Sigma) in a solution of $0.01 \mathrm{M}$ Tris, $0.01 \mathrm{M} \mathrm{NaCl}$, and $0.012 \mathrm{M} \mathrm{NaOAc}$ containing $0.1 \%$ BSA for $1 \mathrm{~h}$ at $37^{\circ} \mathrm{C}$ to digest the glycosaminoglycan chain, thereby exposing the core protein of $\mathrm{DCN}$ before sodium dodecyl sulfate-polyacrylamide gel electrophoresis (SDS-PAGE).

SDS-PAGE and western blotting were performed as described previously [22,23]. The membranes were probed with anti-rabbit DCN polyclonal antibody (Abcam Cat\# ab137508, RRID:AB_2847890; Abcam, Cambridge, MA, USA) for human and mouse samples and anti-rabbit DCN polyclonal antibody (Cat\# PA5-95830, RRID:AB_2807632, ThermoFisher Scientific Japan Ltd.) for rat samples. Anti-rabbit glyceraldehyde 3-phosphate dehydroge- 
nase (GAPDH) polyclonal antibody (Cat\# G9545, RRID:AB_796208; Sigma) was used to demonstrate equal protein loading in each lane.

\subsection{Constructs for the $h D C N-T g$ Line}

All animal and recombinant DNA experiments were approved by the Kanazawa Medical University Ethics Committee for Animal Experiments (authorization No. 2018-3) and Safety Committee for Recombinant DNA Experiments (authorization No. 2018-8). A plasmid in which Pax6-human $\alpha$ A-crystallin (P6a) composite promoter (CPV14) [24] drives $h D C N$ cDNA was generated using the following procedures. Briefly, $h D C N c D N A$ was amplified using the primers; $5^{\prime}$-tggatccgccgccaccatgaaggccactatcatcctc- $3^{\prime}$ and $5^{\prime}$-agaattcttacttatagttccgagttgaatgg- $3^{\prime}$. The fragment was sub-cloned in the pBRBlue vector and confirmed via sequencing. Then, the $h D C N$ fragment was digested using BamHI and EcoRI and sub-cloned in the pCPV14 plasmid. The P6a- $h D C N$-pA fragment, excised using NotI and XbaI, was cloned in the pBRPy-IRES-nLacZpA plasmid (the final product was pBRPy-P6a-hDCN-IRES-nLacZpA). This construct has the following two advantages: 1) $h D C N$ expression was restricted within the crystalline lens using the P6a promoter in mice, which 2) can be readily confirmed using LacZ staining in tissues.

\subsection{Generation of $h D C N-T g$}

The pBRPy-P6a-hDCNiLacZ vector was linearized with PmlI and purified using the QIAquick gel extraction kit (Qiagen Inc.). The fragment was used to generate transgenic mice by injecting into the pronucleus of fertilized eggs (C57BL/6JJmsSlc). Then, the eggs were transferred into the oviduct of pseudo-pregnant mice (Slc:ICR). Offspring were genotyped using the following primer set; $5^{\prime}$ - tacagccatccaccttcagatgt $-3^{\prime}$ and Rv $5^{\prime}$-gccacatatcctgatcttccaga- $3^{\prime}$. The PCR product was $771 \mathrm{bp}$ in length. Offspring harboring the exogenous fragment were bred with the C57BL/6JJmsSlc strain of mice.

\subsection{Histochemical Staining for LacZ with X-Gal}

Three $h D C N-T g$ and three wild-type (WT) mouse heads were collected from mice on postnatal day 2 (PD2) and fixed with 4\% paraformaldehyde (PFA)/phosphate-buffered saline (PBS) (Nacalai Tesque Inc., Kyoto, Japan). The fixed tissue were then rinsed twice in PBS for $20 \mathrm{~min} \times 2$ times and placed in staining media containing $5 \mathrm{mM}$ potassium ferricyanide $/ 5 \mathrm{mM}$ potassium ferrocyanide (Nacalai Tesque Inc.) $1 / \mathrm{mg} / \mathrm{mL} 5$-bromo- 4 chloro-3-indolyl- $\beta$-D-galactoside (X-gal) (Nacalai Tesque Inc.) $/ 0.02 \%$ NP40 (Sigma) $/ 0.01 \%$ deoxycholate (Wako) $/ 1 \mathrm{mM} \mathrm{MgCl} 2$ (Wako) in PBS. The tissues were incubated in staining media overnight in the dark at room temperature. After incubation, the tissues were washed twice with PBS and then post-fixed with $4 \%$ PFA/PBS for $2 \mathrm{~h}$ before paraffin embedding and sectioning. Hematoxylin and eosin (H \& E) staining of the tissue sections was performed for contrast histological observation.

\subsection{Microscopic, Histological, and Immunohistochemical Analyses}

The eyes of 8 and 48-week-old $h D C N-T g$ and WT mice were fixed for $48 \mathrm{~h}$ in Super Fix KY-500 solution ${ }^{\circledR}$ (Kurabo, Tokyo, Japan), embedded in paraffin, and sectioned at approximately $4 \mu \mathrm{m}(n=4)$. Then, the eyes were stained with H \& E. For immunohistochemical analysis, the eyes were immunostained using a tyramide signal amplification $\left(\mathrm{TSA}^{\mathrm{TM}}\right.$ ) kit (Molecular Probes Inc., ThermoFisher Scientific Japan Ltd.), following the manufacturer's protocol and as described previously $[25,26]$. For DCN immunostaining, the sections were treated with target retrieval solution (Dako/Agilent, Santa Clara, CA, USA) following treatment with $0.2 \mathrm{U} / \mathrm{mL}$ protease-free $\mathrm{C}-\mathrm{ABC}$ as described in the section on western blotting to expose the core protein before blocking with a blocking reagent (Molecular Probes Inc., ThermoFisher Scientific Japan Ltd.). DCN was visualized using anti-rabbit DCN polyclonal antibody (ab137508; abcam). The cell nuclei were stained with 4',6-diamidino-2-phenylindole (DAPI) (Fluoroshield Mounting Medium with DAPI: ImmunoBioScience Corp., Mukilteo, WA, USA). For negative controls (NC), rabbit and 
mouse IgG isotype controls (Dako) were used, and the primary antibody was omitted. NC was performed along with the experiments.

\subsection{In Vivo Wound Healing Assay}

The wound healing model was generated in 14-week-old mice as described previously [27]. Briefly, six $h D C N-T g$ and six WT mice were anesthetized via isoflurane USP (Abbott Laboratories Japan, Tokyo, Japan) inhalation. Following topical application of mydriatics, the central anterior lens capsule was pierced once with the blade of a 27-gauge needle to a depth of approximately $2.5 \mathrm{~mm}$ from the corneal surface. After injection, the mice were allowed to heal for 5 and 10 days. The enucleated eye globes were fixed and embedded in paraffin for histological examinations after $\mathrm{H} \&$ E staining. Immunohistochemical analysis using anti- $\alpha \mathrm{SMA} \mathrm{Ab}$ was performed as described in the previous section.

\subsection{Obtaining LEC and Aqueous Humor Samples from Patients with Cataract}

This study was approved by the ethics committee of the Kanazawa Medical University (Approval ID: R263). All patients at the Kanazawa Medical University, Japan, provided informed consent for participation. In addition, this study adhered to the tenets of the Declaration of Helsinki (2004) [28]. In total, 101 cataractous eyes of Japanese patients aged 19-87 years, who underwent cataract surgery at the Kanazawa Medical University between March and December 2015, were prospectively and sequentially examined. Patients with prior history of ocular surgery, trauma, active ocular disease (including retinitis pigmentosa, diabetes, retinal detachment, uveitis, vitreous hemorrhage, and/or receiving steroid medication) were excluded. The type and severity of the cataracts were graded and recorded based on a WHO classification system [29]. Three slit-lamp images were used for grading nuclear opalescence (N0-3), three retroillumination images for cortical cataracts (C0-3), and three retroillumination images for posterior subcapsular (P0-3) cataracts. Each scale on the WHO classification system is a devitalized grade ranging from 0 (clear or opacification less than grade1) to 3 (upper value on the N, C, and P scales).

\subsection{Enzyme-Linked Immunosorbent Assay (ELISA) for DCN in the Aqueous Humor}

The DCN levels in aqueous humor samples were measured using DCN ELISA kits (Sigma) according to the manufacturer's instructions. Briefly, an aqueous humor sample or standard DCN recombinant protein was added to each well and incubated overnight at $4{ }^{\circ} \mathrm{C}$. An anti-human DCN antibody was added following incubation with a streptavidinhorse radish peroxidase-conjugated antibody and substrate solutions. The absorbance at $450 \mathrm{~nm}$ of each well was recorded using an ELISA plate reader (Bio-Rad Laboratories, Hercules, CA, USA). Serial dilutions (0-700 pg/ $\mu \mathrm{L})$ of purified DCN protein were used as standards in each experiment. The detection limits of DCN in the aqueous humor ranged between 0.96 and $700 \mathrm{pg} / \mathrm{mL}$. All experiments were repeated at least thrice, and the mean DCN levels (pg/mL) were calculated and presented.

\subsection{Statistical Methods}

For all quantitative data collected, the statistical analysis was conducted using one-way analysis of variance (ANOVA) test and Tukey's test. The data are presented as mean \pm SD of the indicated number of experiments. Significant differences between the control and treatment groups were defined at $p$-value $<0.05$ for two or more independent experiments.

The correlation between cataract score, age, and DCN protein levels in human aqueous humor or Dcn mRNA levels in human LECs was analyzed using one-factor analysis of variance or Pearson's correlation coefficient, with data expressed as mean \pm standard error (SE). The power analysis to calculate the sample size of this study was performed. All statistical analyses and power analysis were performed using StatMate2.0 (GraphPad Software, Inc. La Jolla, CA, USA), and $p$-values less than 0.05 were considered statistically significant. 


\section{Results}

\subsection{Screening of Gene Expression Profile}

Samples extracted from lens capsules at day 0 (control), and 1 and $2 \mathrm{~W}$ after ECLE from rats were used for microarray analysis. The data for the microarray analysis were deposited in the Gene Expression Omnibus (GEO) database (accession number: GSE152593).

First, among the approximately 28,700 well-substantiated rat genes on the array, 490 genes showed fold change $>2.01 \mathrm{~W}$ and $2 \mathrm{~W}$ after ECLE compared to that in the control (Figure 1).

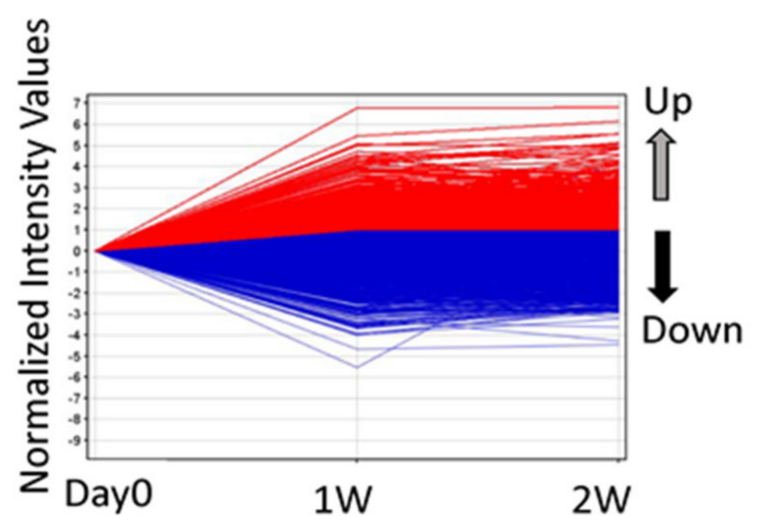

Figure 1. Differences in gene expression profile between 1 week $(\mathrm{W})$ and $2 \mathrm{~W}$ groups after extracapsular clear-lens extraction (ECLE). Scatter plots were used to distinguish the differentially expressed mRNA. Red and blue indicate high and low expression, respectively.

Nine genes showed significant changes of less than 0.5 -fold at $1 \mathrm{~W}$ and greater than 2.0-fold at $2 \mathrm{~W}$ after ECLE compared to that in the control (Figure 1). Compared to that in the control, 504 genes showed significant changes of less than 0.5 -fold $1 \mathrm{~W}$ and $2 \mathrm{~W}$ after ECLE (Figure 1). Table 1 shows the list of the top 30 genes that showed significant changes greater than 2.0-fold in all groups. The most highly upregulated gene common in the three samples was Dcn, which showed more than 100-fold higher expression than the control. Genes encoding collagen type V, I, III, and VI were included in the top 30 genes shown in Table 1. fibronectin 1 ( $F n 1), T p m 2$, and Tgfbi, which are related to EMT, were also included in the top 30 genes shown in Table 1.

Gene Ontology analysis revealed that genes upregulated at both $1 \mathrm{~W}$ and $2 \mathrm{~W}$ were associated with defense response, response to stimuli, development of vasculature, extracellular matrix, regulation of cell migration, and response to stress (Table 2).

Table 3 lists the genes which were downregulated at $1 \mathrm{~W}$ and upregulated at $2 \mathrm{~W}$ after ECLE. Genes related to the differentiation of lens fiber, including gamma crystallin (Cryg) and filensin (Bfsp1), were initially downregulated and subsequently upregulated during PCO development.

Gene Ontology analysis revealed that genes downregulated at $1 \mathrm{~W}$ and upregulated at $2 \mathrm{~W}$ were associated with the structural constituent of the eye, lens development in the camera-type eye, lens fiber cell differentiation, and sensory perception (Table 4). 
Table 1. Lists of top 30 genes which were $>2.0$ times up-regulated at $1 \mathrm{~W}$ and $2 \mathrm{~W}$ after ECLE.

\begin{tabular}{|c|c|c|c|c|c|}
\hline & $\begin{array}{c}\text { Gene } \\
\text { Symbol }\end{array}$ & Gene Description & & Gene Symbol & Gene Description \\
\hline 1 & Dcn & decorin & 16 & $R T 1-D a$ & RT1 class II, locus Da \\
\hline 2 & Col5a2 & collagen, type $\mathrm{V}$, alpha 2 & 17 & $C y b b$ & cytochrome b-245, beta polypeptide \\
\hline 3 & Fn1 & fibronectin 1 & 18 & Col6a3 & collagen, type VI, alpha 3 \\
\hline 4 & Cyr61 & cysteine-rich, angiogenic inducer, 61 & 19 & Rnase4 & ribonuclease, RNase A family 4 \\
\hline 5 & Col5a2 & collagen, type $\mathrm{V}$, alpha 2 & 20 & Runx1 & runt-related transcription factor 1 \\
\hline 6 & Col1a1 & collagen, type I, alpha 1 & 21 & Tpm2 & tropomyosin 2 , beta \\
\hline 7 & Mylk & myosin light chain kinase & 22 & Ptgs2 & prostaglandin-endoperoxide synthase 2 \\
\hline 8 & Col3a1 & collagen, type III, alpha 1 & 23 & $T g f b i$ & transforming growth factor, beta-induced \\
\hline 9 & $\operatorname{Actg} 2$ & $\begin{array}{l}\text { actin, gamma } 2 \text {, smooth } \\
\text { muscle, enteric }\end{array}$ & 24 & $M g p$ & matrix Gla protein \\
\hline 10 & Gbp2 & $\begin{array}{l}\text { guanylate binding protein 2, } \\
\text { interferon-inducible }\end{array}$ & 25 & $E d n r b$ & endothelin receptor type B \\
\hline 11 & Emp1 & epithelial membrane protein 1 & 26 & Lyz2 & lysozyme 2 \\
\hline 12 & Gpnmb & glycoprotein (transmembrane) $\mathrm{nmb}$ & 27 & Car3 & carbonic anhydrase 3 \\
\hline 13 & $C d 74$ & $\begin{array}{l}\text { Cd74 molecule, major } \\
\text { histocompatibility complex }\end{array}$ & 28 & Sfrp2 & secreted frizzled-related protein 2 \\
\hline 14 & Dct & dopachrome tautomerase & 29 & Fcrls & Fc receptor-like $S$, scavenger receptor \\
\hline 15 & Scn7a & $\begin{array}{c}\text { sodium channel, voltage-gated, type } \\
\text { VII, alpha }\end{array}$ & 30 & Ifitm1 & $\begin{array}{l}\text { interferon-induced transmembrane } \\
\text { protein } 1\end{array}$ \\
\hline
\end{tabular}

Table 2. Gene Ontology (GO) analysis; $1 \mathrm{~W}$ and $2 \mathrm{~W}>$ Day 0: $>2.0$ times.

\begin{tabular}{cc}
\hline GO Accession Number & GO Term \\
\hline GO:0006952 | GO:0002217 | GO:0042829 & Defense response \\
\hline GO:0009605 & Response to external stimulus \\
\hline GO:0051707 | GO:0009613 | GO:0042828 & Response to other organisms \\
\hline GO:0009607 & Response to biotic stimulus \\
\hline GO:0050896 | GO:0051869 & Response to stimulus \\
\hline GO:0043207 & Vasculature development \\
\hline GO:0001944 & Extracellular matrix \\
\hline GO:0031012 & Regulation of cell migration \\
\hline GO:0030334 & Response to stress \\
\hline GO:0006950
\end{tabular}


Table 3. Lists of genes which were $<0.5$ times down-regulated at $1 \mathrm{~W}$ and $>2.0$ times up-regulated at $2 \mathrm{~W}$ after extracapsular clear lens extraction (ECLE).

\begin{tabular}{cccc}
\hline Gene Symbol & Gene Description & $\mathbf{1 ~ W}$ & $\mathbf{2 ~ W}$ \\
\hline Crygb & crystallin, gamma B & 0.021 & 2.292 \\
\hline Crygc & crystallin, gamma C & 0.139 & 4.448 \\
\hline Crygd & crystallin, gamma D & 0.148 & 2.450 \\
\hline Colq & $\begin{array}{c}\text { collagen-like tail subunit (single } \\
\text { strand of homotrimer) of asymmetric } \\
\text { acetylcholinesterase }\end{array}$ & 0.300 & 2.324 \\
\hline Bfsp1 & $\begin{array}{c}\text { beaded filament structural protein 1, } \\
\text { filensin }\end{array}$ & 0.321 & 11.611 \\
\hline Slc24a2 & $\begin{array}{c}\text { solute carrier family 24 } \\
\text { (sodium/potassium/calcium } \\
\text { exchanger), member 2 }\end{array}$ & 0.323 & 5.878 \\
\hline Snhg11 & small nucleolar RNA host gene 11 \\
(non-protein coding) & 0.380 & 6.667 \\
\hline Slc46a3 & solute carrier family 46, member 3 & 0.423 & 2.121 \\
\hline Anxa9 & annexin A9 & 0.466 & 2.296 \\
\hline
\end{tabular}

Table 4. Gene Ontology (GO) analysis.

\begin{tabular}{cc}
\hline GO Accession & GO Term \\
\hline GO:0005212 & Structural constituent of eye \\
\hline GO:0002088 & Lens development in camera-type eye \\
\hline GO:0007601 & Visual perception \\
\hline GO:0070306 & Lens fiber cell differentiation \\
\hline GO:0050953 & Sensory perception of light stimulus \\
\hline GO:0005198 & Camera-type eye development \\
\hline GO:0043010 | GO:0001747 | GO0031075 & Eye development \\
\hline GO:0001654 | GO:0042460 & Lens fiber cell development \\
\hline GO:0070307 & Sensory perception \\
\hline GO:0007600 &
\end{tabular}

3.2. Confirmation of Gene Upregulation Using RT-qPCR and Western Blotting in Rat and Mouse PCO Models

We confirmed the results of microarray using RT-qPCR and western blotting. Expression of the Dcn mRNA and DCN increased significantly in rat PCO at 1 and $2 \mathrm{~W}$ (Figure $2 \mathrm{a}, \mathrm{b} ;{ }^{*} p<0.0003$ ). Similarly, Dcn mRNA level increased significantly in mouse PCO at $1 \mathrm{~W}$ (Figure $2 \mathrm{c} ;{ }^{*} p<0.0025$ ). Furthermore, the expression of Tgfbi and Tpm $2 \mathrm{mRNAs}$ increased significantly in rat PCO $1 \mathrm{~W}$ after ECLE (Figure 2). 
A

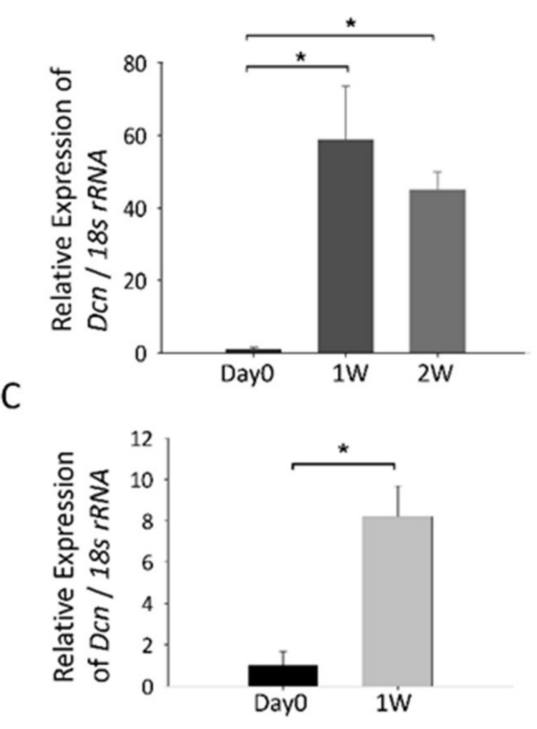

B

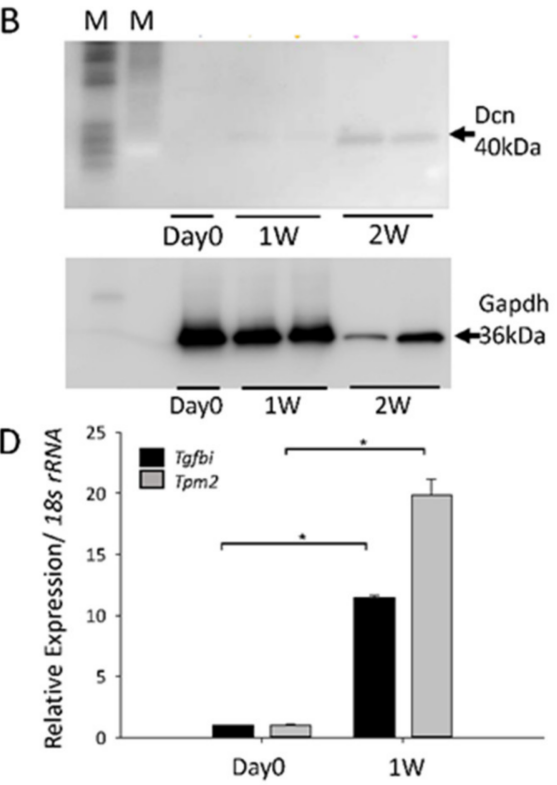

Figure 2. RT-qPCR validation of $D c n$ and Tpm2 expression in rat or mouse posterior capsule opacification (PCO). (A) Expression of Dcn mRNA in rat PCO samples 1 and 2 weeks (W) after extracapsular clear lens extraction (ECLE) was compared to that on day $0\left({ }^{*} p<0.0003\right)$ (B) Expression of $D C N$ protein in mouse PCO samples 1 and 2 weeks after ECLE compared to that on day $0\left({ }^{*} p<0.0025\right)$ (C) Expression of Dcn mRNA in mouse PCO samples 1 week after mouse PCO onset was compared to that on day $0\left({ }^{*} p<0.0025\right)$ (D) Relative expression of Tgfbi and Tpm 2 mRNAs 1 week after mouse PCO onset was compared to that on day $0\left({ }^{*} p<0.000001\right)$. Data were from three experiments and were reported as mean \pm S.D $(n=3)$.

\subsection{Effect of TGF $\beta$ and FGF2 on the Expression of Den and Tpm1 in MLECs and SRA-HLECs}

TGF $\beta-2$ and FGF2 are involved in the regulation of PCO and EMT. To investigate whether the expression of Dcn was affected in MLECs or SRA-HLECs treated with TGF $\beta$ or TGF $\beta$ plus FGF, we selected TGF $\beta-2$, the major isoform expressed in eyes that contributes to PCO [1], and FGF2, the most potent of all FGFs, for further analyses.

Dcn mRNA level increased in response to FGF2, and reduced in response to TGF $\beta-2$ and a combination of FGF2 and TGF $\beta-2$ on days 2 and 4 in MLECs (Figure $3 a,{ }^{*} p<0.05$; ** $p<0.01$ ). Furthermore, Dcn mRNA level increased in response to FGF2, and reduced in response to TGF $\beta-2$ and a combination of FGF2 and TGF $\beta-2$ on days 2 and 4 in MLECs (Figure $3 a,{ }^{*} p<0.05 ;{ }^{* *} p<0.01$ ). Similarly, the expression of Dcn mRNA increased significantly in SRA-HLEC after treatment with FGF2 (Figure $3 b,{ }^{*} p<0.004 ;{ }^{* *} p<0.05$ ).

\subsection{Effect of $h D C N$ Overexpression on TGF $\beta$-Induced Tpm 1 Upregulation}

We observed that GFP was expressed in the GFP-vector and GFP- $h D C N$-transfected SRA-HLECs (Figure 4a). In GFP-hDCN-overexpressing SRA-HLECs, the expression of $h D C N$ mRNA increased in SRA-HLECs and $\mathrm{hDCN}$ was secreted in the culture medium (Figure $\left.4 \mathrm{~b}, \mathrm{c} ;{ }^{*} p<0.05\right)$. Expression of the Tpm1 mRNA increased significantly in GFPvector-transfected SRA-HLECs after treatment with TGF $\beta-2$. However, $h D C N$ overexpression significantly suppressed the upregulation of Tpm 1 mRNA in GFP- $h D C N$-transfected SRA-HLECs (Figure 4d). Alternatively, FGF2 treatment did not affect the expression of Tpm1 in GFP-hDCN-overexpressing SRA-HLECs (Figure $4 \mathrm{~d} ;{ }^{*} p<0.001,{ }^{* *} p<0.02$ ). 
A

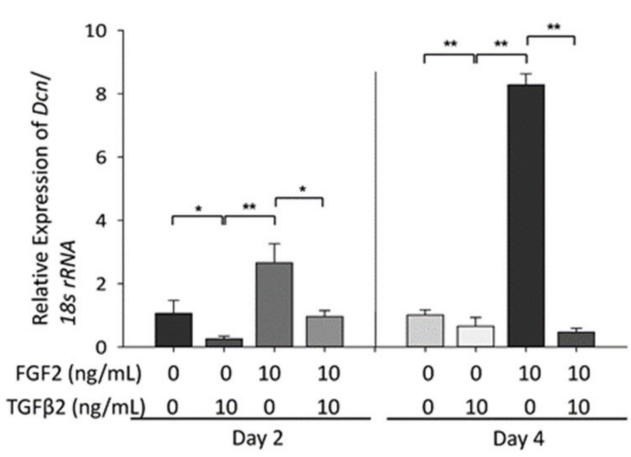

B

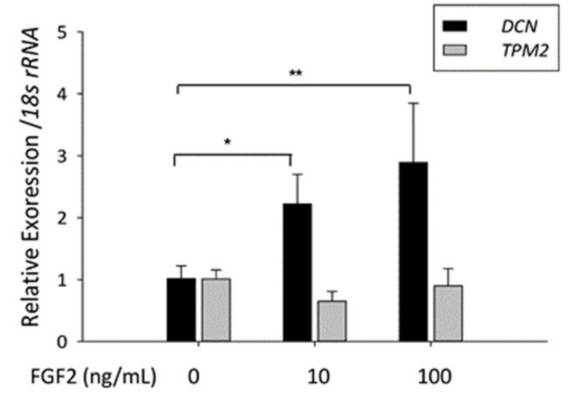

Figure 3. Expression of Dcn and Tpm1 in cultured mouse lens epithelial cells (MLECs) and human mouse lens epithelial cells (HLECs) after treatment with FGF2 with/without TGF $\beta-2$. (A) Cultured MLECs were plated in 35-mm dishes at the density of $1 \times 10^{5}$ in Dulbecco's modified Eagle's media (DMEM) with $10 \%$ FBS for $24 \mathrm{~h}$. LECs were treated with $10 \mathrm{ng} / \mathrm{mL}$ TGF $\beta-2$ and/or $100 \mathrm{ng} / \mathrm{mL}$ FGF2 in DMEM containing $1 \%$ FBS for 2 and 4 days. The relative quantity of Dcn mRNA was determined using RT-qPCR analysis. ${ }^{*} p<0.004,{ }^{* *} p<0.001$. (B) Cultured HLECs were plated in 35-mm dishes at the density of $8 \times 10^{4}$ in DMEM with $20 \%$ FBS for $24 \mathrm{~h}$. LECs were treated with $0-100 \mathrm{ng} / \mathrm{mL}$ FGF2 in DMEM containing $1 \%$ FBS for 2 days. Relative quantity of Dcn and Tpm 1 mRNA was determined using RT-qPCR analysis. ${ }^{*} p<0.004,{ }^{* *} p<0.05$. Data were from three experiments and were reported as mean \pm S.D. M: marker.

A

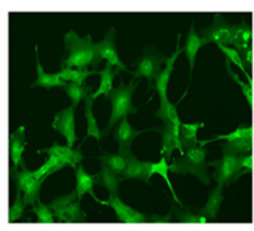

Vec

C

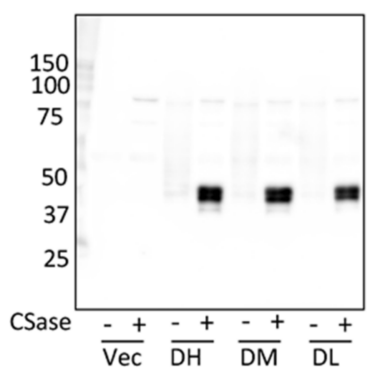

D
B
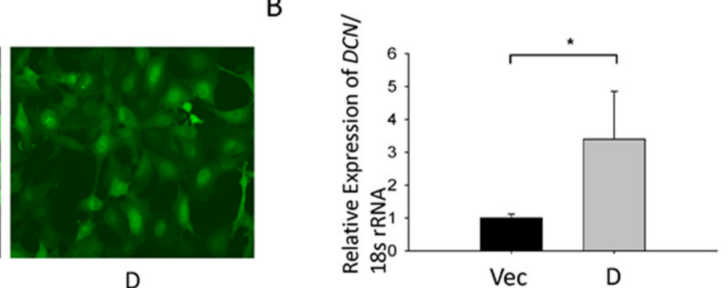

D

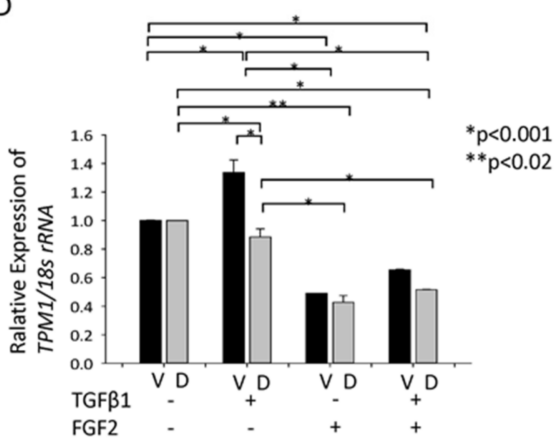

Figure 4. Effect of overexpression of hDCN in HLECs. (A) We monitored the transduction efficiency of GFP-vector (Vec) and GFP-hDCN (D) by observing the GFP-expressing cells within the live cell population. (B) RT-qPCR was performed to confirm the expression level of $h D C N$ mRNA in GFP-vector (Vec) and GFP-hDCN (D)-overexpressing SRA-HLECs. ${ }^{*} p<0.05$. (C) The collected culture supernatant was subjected to SDS-PAGE. In total, $250 \mathrm{ng}$ protein was loaded per lane after concentrating the culture supernatant and digesting the GAG chain with or without proteasefree chondroitinase (CSase). The secretion of DCN from SRA-HLEC overexpressing GFP-hDCN (Expression level: DH, High; DM, moderate; DL, Low) or GFP-Vec (Vec) was confirmed using western blotting. The core protein of DCN was approximately $50 \mathrm{kDa}$. (D) Cultured GFP-vector (V) or GFP-hDCN (D)-transfected SRA-HLECs were plated in 35-mm dishes at the density of $8 \times 10^{4}$ in DMEM with $20 \%$ FBS for $24 \mathrm{~h}$. LECs were treated with $10 \mathrm{ng} / \mathrm{mL}$ TGF $\beta-2$ and/or $100 \mathrm{ng} / \mathrm{mL}$ FGF2 in DMEM containing 1\% FBS and incubated for 2 days. TPM1 mRNA level was analyzed using RT-qPCR. PC; Positive control, human dermis (1 $\mu \mathrm{g} / \mathrm{lane}) .{ }^{*} p<0.001,{ }^{* *} p<0.02$. 


\subsection{Lens Morphology of hDCN-Tg Mice}

Compared to that in WT mice, histological changes in the lenses on PD2 were not observed in $h D C N-T g$ mice (Figure $5 \mathrm{a}, \mathrm{b}$ ). Expression of $D C N$ in $h D C N-T g$ animals on PD2 was confirmed using histochemical staining for lacZ with X-Gal and immunostaining using an anti-DCN antibody. As shown in Figure 5c, X-gal staining was observed in the cytoplasm of LECs at the equatorial to bow region and in the primary lens fiber in $h D C N-T g$ mice on PD. However, X-gal staining was not observed in the lens tissue of WT mice (Figure $5 d$ ). Similarly, DCN was strongly immunostained in newly formed lens fibers of $h D C N-T g$ animals on PD2 (Figure 5e). However, DCN was not immunostained in the lenses of WT mice (Figure 5f). The difference in the X-gal and anti-DCN immunostaining sites is because of the inability of X-gal to penetrate to the center of the lens. Histological changes were not observed in the lenses of 8-, 25-, and 48-week-old $h D C N-T g$ and WT mice (25-week-old mice: Figure 5g,h). These results suggested that hDCN-overexpression did not affect lens development and differentiation.
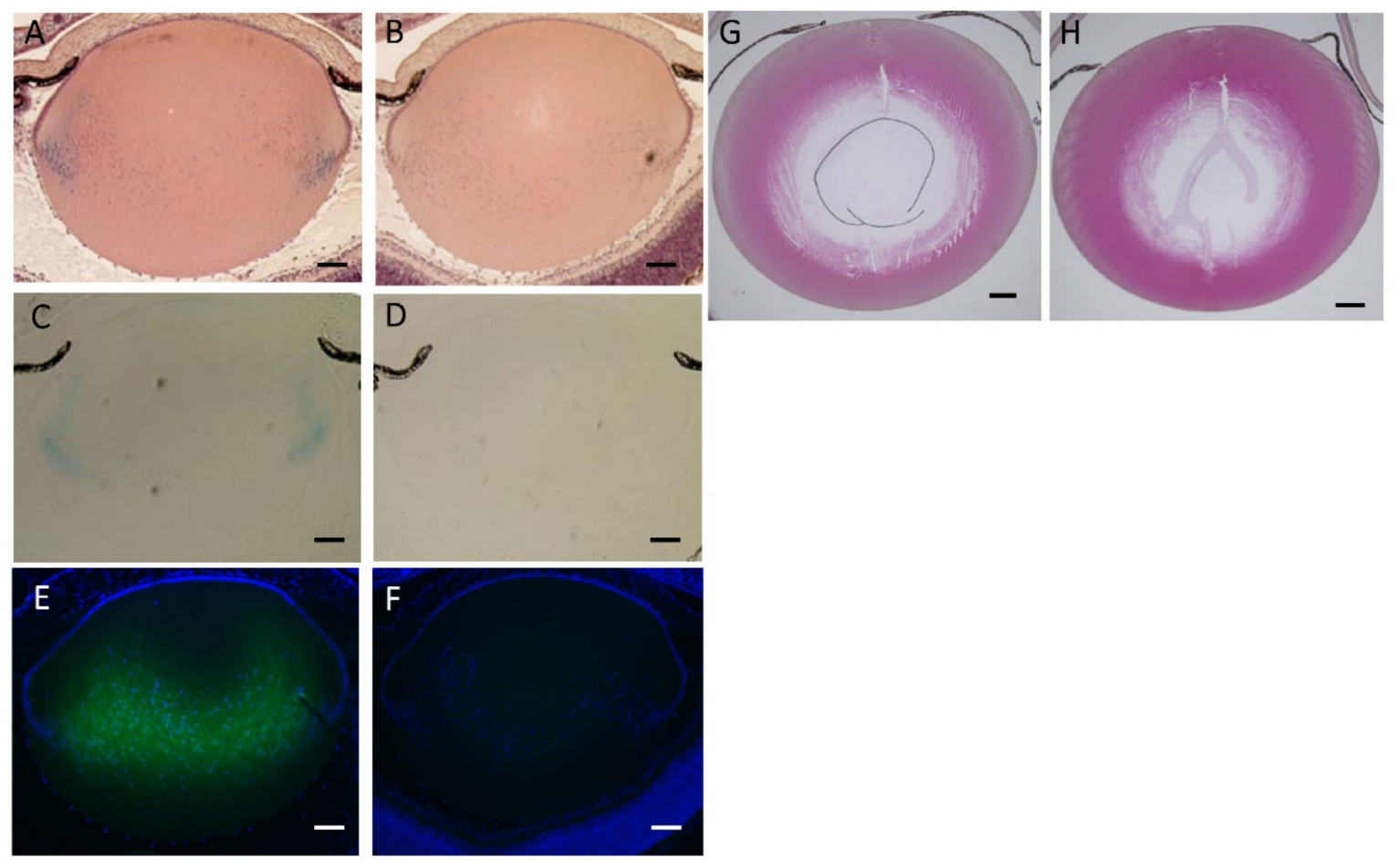

Figure 5. $\beta$-Galactosidase expression and histochemical analysis of lenses in $h D C N-T g$ animals. The findings regarding lens tissue in $h D C N-T g$ (A) newborn mice (PD1) did not differ from those in WT (B). (C) Lens images showing the expression of $\beta$-galactosidase in the anterior epithelial cells and primary lens fiber cells of the newborn $h D C N-T g$ mouse lens, revealed by X-gal staining. (D) Control sections from WT mice at PD1 were not stained with X-gal. (E) DCN was strongly immunostained in the lens fiber of the $h D C N-T g$ animal at PD1, suggesting that DCN secreted from LECs perfused into the lens fiber. (F) DCN immunostaining signal was undetectable or negative at PD1 in the lens of WT mice at PD1. Adult lenses in 25-week-old hDCN-Tg animals (G) did not show lens fiber damage and epithelial cell changes and did not differ from those in WT (H). Scale bar $=200 \mu \mathrm{m}$ in $\mathrm{a}, \mathrm{b}, \mathrm{c}, \mathrm{d}, \mathrm{e}$, and $\mathrm{f} ; 100 \mu \mathrm{m}$ in $\mathrm{g}$ and $\mathrm{h}$.

\subsection{Effect of hDCN Overexpression on Wound Healing on Lens Surface In Vivo}

The wounded areas in the lens surface revealed fibroblast-like tissue changes, indicating EMT in WT and $h D C N-T g$ animals (Figure 6). On days 5 (Figure 6a,c) and 10 (Figure $6 \mathrm{~b}, \mathrm{~d}$ ), fibroblastic changes around the wounded area were smaller in $\mathrm{hDCN}-\mathrm{Tg}$ (Figure $6 c, d$ ) than in WT mice after needle puncture (Figure 6a,b). 

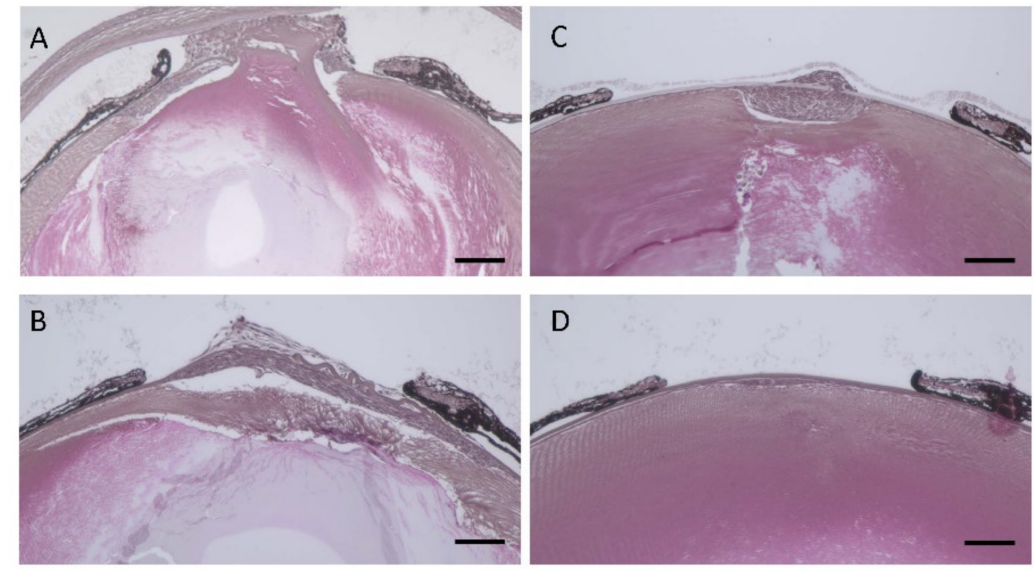

Figure 6. $h D C N-T g$ suppressed epithelial-mesenchymal transition (EMT) and fibroblastic changes in injured mouse lenses. Paraffin sections of the lenses of WT $(\mathbf{A}, \mathbf{B})$ and $h D C N-T g$ animals $(\mathbf{C}, \mathbf{D})$ with injury at 5 and 10 days were prepared and stained with H \& E. Scale bar, $100 \mu \mathrm{m}$. Results are representative of six independent lenses.

Fibroblastic LECs at the wound surface were immunopositive for $\alpha$ SMA on days 5 and 10 in both $h D C N-T g$ and WT mice (Figure 7a-d). The $\alpha$ SMA-immunopositive area in $h D C N-T g$ mice (Figure 7c,d) was smaller than that in WT mice (Figure 7a,b).
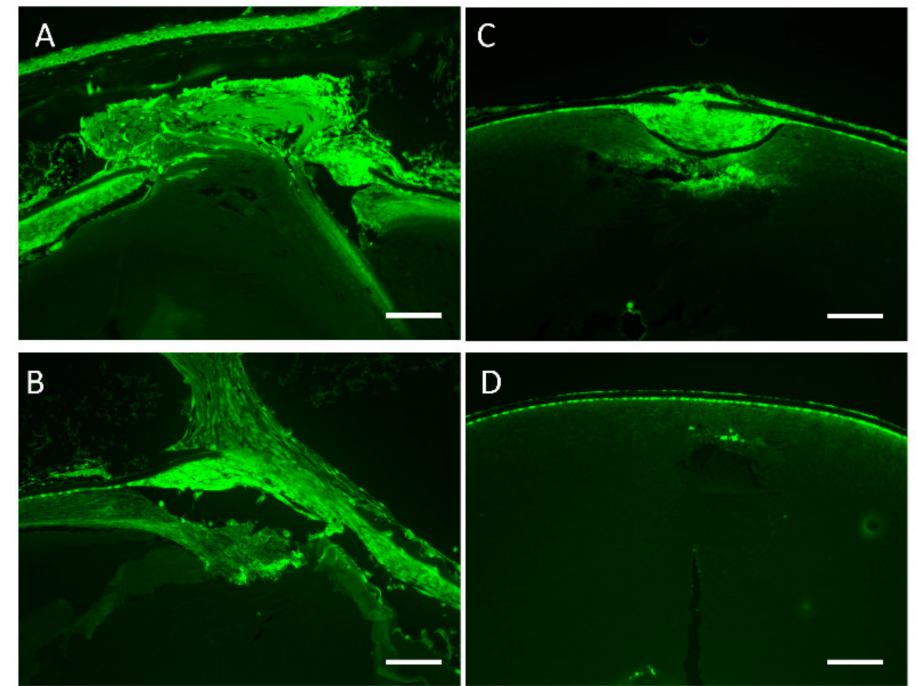

Figure 7. $\alpha$-SMA was expressed in fibroblastic tissues observed in $h D C N-T g$ and WT animals. Paraffin sections of lenses of WT (A,B) and $h D C N-T g$ animals (C,D) with injury at $5(\mathbf{A}, \mathbf{C})$ and $10(\mathbf{B}, \mathbf{D})$ days were prepared and immunostained with anti- $\alpha \mathrm{SMA} \mathrm{Ab}$. Scale bar, $100 \mu \mathrm{m}$. Results are representative of six independent lenses.

3.7. Relationship between Expression of DCN, Severity of Cataract, and Age in Aqueous Humor or Human LECs of Patients with Cataract

We examined whether the expression levels of DCN were associated with human cataracts and aging. The sample size to enroll in this study was estimated by the adequate power analysis. However, no significant associations were noted between age (Figure 8a) or the severity of the three major types of cataracts (cortical, nuclear, and posterior subcapsular) and Dcn mRNA levels in human LECs of patients with cataract (data not shown). Although DCN was detected in human aqueous humor, its concentration varied among subjects, showing no association with age, cataract subtype, or grade (range of concentration: 111.0 639.2; mean: $403.5 \pm 126.3$ ). Significant associations between age (Figure 8b) or severity of the three major types of cataracts (cortical, nuclear, and posterior subcapsular) 
and DCN protein levels in human aqueous humor of patients with cataracts were not observed (data not shown).

A

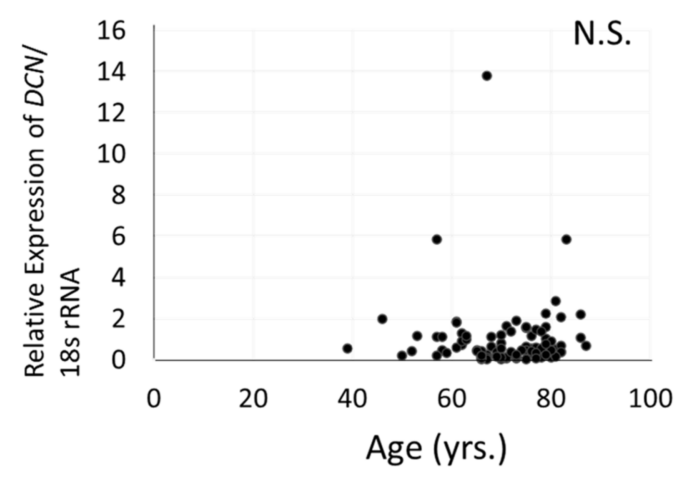

B

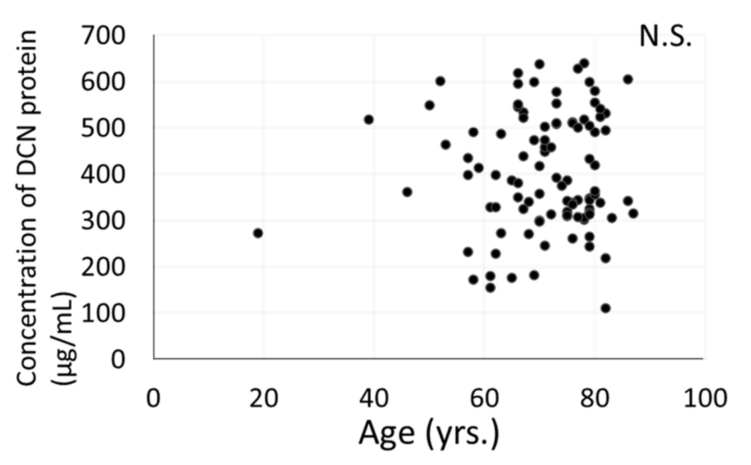

Figure 8. Relationship between age and Dcn mRNA expression in human LECs, and between age and concentration of DCN protein in human aqueous humor. RT-qPCR validation of Dcn mRNA expression in human LECs (A) and ELISA for DCN concentration in aqueous humor from patients with cataract (B) compared to that in the control (human LECs obtained from the clear lens after vitrectomy for removal of epiretinal membrane). N.S.: not significant; yrs: years-old.

\section{Discussion}

In the present study, we investigated the gene expression profiles of rat PCO to understand the mechanism underlying its progression. Using microarray analysis, we identified several LEC genes, expression of which was modulated in response to ECLE. Our experimental data showed that Dcn was highly upregulated in rat and mouse PCO. Furthermore, the expression of other PCO-related genes such as Tgfbi, a Tgf- $\beta$-induced extracellular matrix (ECM) $[7,21]$, and Tpm2, also increased in DNA microarray analysis, which was confirmed using RT-qPCR in rat and mouse PCO. In our previous study, Tpm1 and Tpm 2 were upregulated in the multilayered, spindle-shaped LECs in a rat model of PCO, human cataracts with anterior subcapsular fibrosis, and human differentiated LECs in a dislocated lens capsule [18]. In this study, Tpm2 expression increased similarly in rat PCO, confirming that our rat and mouse PCO models were stable. Gene Ontology analysis revealed that the function of upregulated genes in rat PCO both $1 \mathrm{~W}$ and $2 \mathrm{~W}$ after ECLE were associated with defense response, response to stimuli, development of vasculature, extracellular matrix, regulation of cell migration, and stress response. After cataract surgery, genes related to the wound healing process appear to be induced rapidly in LECs. The functions of genes that were downregulated at $1 \mathrm{~W}$ and upregulated at $2 \mathrm{~W}$ after rat ECLE were associated with differentiation of lens fiber and lens development, such as $\gamma$-crystallin and filensin. After ECLE, EMT may start in the early stage of PCO and continue thereafter. In contrast, differentiation and regeneration of lens fiber may start late during rat $\mathrm{PCO}$ progression.

Using in situ hybridization, previous studies have shown that DCN mRNA is expressed in human postoperative LEC tissues with anterior capsular opacification [30]. In this study, Dcn was also highly expressed in rat and mouse PCO tissues. Initially, we speculated that DCN was related to EMT and fibrosis, similar to Tpm as reported previously $[12,18,27]$. Expression of Tpm increased after the addition of TGF $\beta-2$ and decreased after the addition of FGF2 in cultured MLEC and SRA-HLEC (SRA01/04) [31]. However, our study revealed that the expression of Dcn mRNA increased after the addition of FGF2 and decreased after the addition of TGF $\beta-2$ in cultured MLECs and SRA-HLECs. The effect of TGF $\beta-2$ and FGF2 administration on Dcn expression was opposite to the effect on Tpm expression. DCN, a member of the small leucine-rich proteoglycan gene family containing leucine repeats with a glycosaminoglycan chain that harbors one chondroitin/dermatan sulfate (DS) side chain at its N-terminus, was originally named because of its ability to 
"decorate" collagen fibrils, thereby regulating fibrillogenesis, a key mechanism of matrix assembly and homeostasis [32,33]. Other studies have shown that DCN regulates the TGF $\beta$ signaling pathway and inhibits the growth of various tumor cells [34]. DCN suppresses tumor cell-mediated angiogenesis by inhibiting the endogenous production of vascular endothelial cell growth factor [35], similar to neutralizing antibodies directed toward the epidermal growth factor receptor (EGFR) [36]. Furthermore, DS from proteoglycans contributes to the signaling behavior of FGF2 [37] and hepatocyte growth factor/scatter factor [38]. Penc et al. (1998) demonstrated that DS released during wound repair can also activate FGF2 signaling [37]. FGF2 and TGF $\beta$ are related to the progression of PCO after cataract surgery $[1,39,40]$. After lens extraction surgery, FGF2 and TGF $\beta$ were upregulated in rabbit aqueous humor, while differentiation/proliferation and EMT of LEC were associated with PCO [40]. Hence, we speculated that DCN may be associated with the differentiation of LECs, but not EMT of LEC, as DCN expression increased in normal LEC treated with FGF2. We reported that TGF $\beta$-2 induced epithelial-myofibroblastic transition in LEC and myofibroblast-like alternation with Tpm-positivity [12]. It is unclear whether DCN suppresses EMT, while DCN expression is reduced by TGF $\beta-2$ in LEC, accompanied by EMT.

We generated $h D C N-T g$ mice to confirm the role of DCN in lens development, PCO, or EMT. Overexpression of $h D C N$ in the lens of $h D C N-T g$ mice did not affect the development, growth, differentiation, and morphology of the lens. These results suggest that administration or overexpression of DCN did not adversely affect lens development and histology. In contrast, this study showed that pathological wound healing, such as fibroblastic EMT-like changes in a model of mouse lens injury was less severe in $h D C N-T g$ than in WT animals, suggesting that overexpression of $D C N$ delays abnormal wound healing in mouse lenses and that DCN plays a protective role in the induction of pathological EMT in lenses. DCN expression increased in mouse and rat PCO tissues. We speculated that the upregulation of $D C N$ was induced by FGF2, which may play a protective role against fibroblastic changes of LECs after cataract surgery. Reports show that DCN reduces subconjunctival tissue scarring [41] and intraocular pressure via fibrinolysis of the scarred trabecular meshwork [42] in animal models [43]. It modulates matrix metalloproteinase (MMP) activity by increasing levels of plasminogen [44], favoring higher ECM turnover and degradation. Indeed, DCN increases MMP-2 and MMP-9 levels, reduces extracellular matrix deposition [45], and attenuates fibrotic changes in animal models of many pathological conditions, including proliferative vitreoretinopathy [46], renal fibrosis [47], and spinal cord injury [48]. DCN is induced in residual lens epithelial cells after ECLE and participates in regulating PCO formation. The overexpression of $D C N$ participates in regulating the anti-fibroblastic pathways to protect against surgical stress and participates in regulating the EMT, and the migration of residual capsular epithelial cells by inhibiting the action of TGF $\beta$ and Tpm. Thus, the addition or induction of DCN may inhibit the fibroblastic and EMT-associated changes observed in PCO.

Nevertheless, studies regarding $D C N$ expression and the effects of its expression levels in human LECs before cataract surgery are lacking. DCN is present and secreted in human anterior aqueous humor and is expressed in human cataractous LECs. In age-related cataracts, DCN concentrations in human anterior aqueous humor and DCN expression in HLEC did not correlate with age, and opacity type or grade. It is of course cumbersome to analyze the level of $D C N$ in human PCO samples and aqueous humor after cataract surgery in vivo. Nevertheless, the results of our in vitro and coupled with in vivo experimentation with $D C N$ transgenic mice, adds weight that DCN is secreted into the aqueous humor and can play an important role in the human PCO or wound healing process in human LEC. We recognize that further studies are required to detail the exact contribution of DCN in human lens/LECs health.

Currently, there is no effective method for predicting who will develop PCO or to prevent its occurrence, and eradication of the disease remains an unmet goal in ophthalmology. Certain molecules, such as cytotoxic chemicals, or distilled water may non-specifically in- 
duce cell death during cataract surgery and influence the surrounding ocular tissues $[49,50]$. Aberrant TGF $\beta$ signaling plays a major role in the EMT of cells akin to its role in the development of human PCO. Thus, drugs and molecules which inhibit TGF $\beta$ signaling, myofibroblasts and EMT, should be considered for the treatment of PCO [27,31,51,52]. Based on the findings obtained in this study, overexpression of $D C N$ in animal models could help further expand data that may ultimately lead to clinical studies and therapeutic interventions.

However, some limitations should be noted. First, experiments for the addition or injection of DCN are required, because DCN is a secreted protein. Thus, we are planning to produce a DCN recombinant protein for further study. Second, PCO $h D C N-T g$ mice should be generated and analyzed. Third, we have not analyzed the levels of human DCN expression by cataract grading, because the number of human samples was not adequate. It may be necessary to study the relationship between human cataracts and DCN.

\section{Conclusions}

In conclusion, this study revealed that the expression of DCN mRNA and protein increased in LECs in animal models of PCO. The development of new therapies for reducing fibrosis and pathological EMT induced by wound healing responses and PCO are necessary to maintain quality of vision after cataract surgery. We believe that administration of DCN or other surgical treatments will help in further reducing secondary cataract and surgical failure by minimizing postoperative PCO or scarring.

Author Contributions: All authors contributed to the study conception and design. Conceptualization, E.K. (Eri Kubo). and S.S.; methodology, E.K. (Etsuko Kiyokawa), S.S., S.O., and Y.Y.; validation, E.K. (Eri Kubo), D.P.S., H.S. and H.Y.; formal analysis, E.Kubo.; investigation, E.K. (Eri Kubo) and S.S.; resources, S.O., Y.Y. and D.P.S.; data curation, E.K. (Eri Kubo) and N.S.; writing-original draft preparation, E.Kubo. and S.S.; writing — review and editing, S.O., Y.Y., D.P.S., and S.S.; visualization, S.S.; supervision, H.Y. and H.S.; project administration, S.S.; funding acquisition, E.K. (Eri Kubo), D.P.S., and S.S. All authors have read and agreed to the published version of the manuscript.

Funding: This work was supported by a grant provided by JSPS Grants-in-Aid for Scientific Research C 23592588 (to S.S.), the National Eye Institute, National Institute of Health [grant number EY024589, (to D.P.S.); and Research for Preventing Blindness (to D.P.S.).

Institutional Review Board Statement: All animal and recombinant DNA experiments were approved by the Kanazawa Medical University Ethics Committee for Animal Experiments (Approval ID: 2018-3; Date: 1 April 2018) and Safety Committee for Recombinant DNA Experiments (Approval ID: 2018-8; Date: 1 April 2018) and were conducted in accordance with the National Institutes of Health Guide for the Care and Use of Laboratory Animals and the Institutional Guidelines for Laboratory Animals from the Kanazawa Medical University. The study on humans was conducted according to the guidelines of the Declaration of Helsinki, and approved by the ethics committee of the Kanazawa Medical University (Approval ID: R263; 17 March 2015).

Informed Consent Statement: Informed consent was obtained from all subjects involved in the study. Written informed consent has been obtained from the patient(s) to publish this paper.

Data Availability Statement: The data for the microarray analysis were deposited in the Gene Expression Omnibus (GEO) database (accession number: GSE152593).

Acknowledgments: Human LECs (SRA01/04: SRA-HLECs) were kindly gifted by Nobuhiro Ibaraki (Ibaraki Eye Clinic, Tochigi, Japan).

Conflicts of Interest: The authors declare no conflict of interest.

\section{References}

1. Wormstone, I.M. Posterior capsule opacification: A cell biological perspective. Exp. Eye Res. 2002, 74, 337-347. [CrossRef] [PubMed]

2. Luo, Y.; Lu, Y.; Lu, G.; Wang, M. Primary posterior capsulorhexis with anterior vitrectomy in preventing posterior capsule opacification in pediatric cataract microsurgery. Microsurgery 2008, 28, 113-116. [CrossRef] [PubMed] 
3. Ben Ezra, D.; Cohen, E. Posterior capsulectomy in pediatric cataract surgery: The necessity of a choice. Ophthalmology 1997, 104, 2168-2174. [CrossRef]

4. Nibourg, L.M.; Sharma, P.K.; van Kooten, T.G.; Koopmans, S.A. Changes in lens stiffness due to capsular opacification in accommodative lens refilling. Exp. Eye Res. 2015, 134, 148-154. [CrossRef] [PubMed]

5. De Iongh, R.U.; Lovicu, F.J.; Overbeek, P.A.; Schneider, M.D.; Joya, J.; Hardeman, E.D.; McAvoy, J.W. Requirement for TGFbeta receptor signaling during terminal lens fiber differentiation. Development 2001, 128, 3995-4010. [PubMed]

6. De Iongh, R.U.; Wederell, E.; Lovicu, F.J.; McAvoy, J.W. Transforming growth factor-beta-induced epithelial-mesenchymal transition in the lens: A model for cataract formation. Cells Tissues Organs 2005, 179, 43-55. [CrossRef] [PubMed]

7. Lee, E.H.; Seomun, Y.; Hwang, K.H.; Kim, J.E.; Kim, I.S.; Kim, J.H.; Joo, C.K. Overexpression of the transforming growth factor-beta-inducible gene betaig-h3 in anterior polar cataracts. Investig. Ophthalmol. Vis. Sci. 2000, 41, 1840-1845.

8. Lovicu, F.J.; Schulz, M.W.; Hales, A.M.; Vincent, L.N.; Overbeek, P.A.; Chamberlain, C.G.; McAvoy, J.W. TGFbeta induces morphological and molecular changes similar to human anterior subcapsular cataract. Br. J. Ophthalmol. 2002, 86, 220-226. [CrossRef]

9. Saika, S.; Miyamoto, T.; Ishida, I.; Shirai, K.; Ohnishi, Y.; Ooshima, A.; McAvoy, J.W. TGFbeta-Smad signalling in postoperative human lens epithelial cells. Br. J. Ophthalmol. 2002, 86, 1428-1433. [CrossRef]

10. Medvedovic, M.; Tomlinson, C.R.; Call, M.K.; Grogg, M.; Tsonis, P.A. Gene expression and discovery during lens regeneration in mouse: Regulation of epithelial to mesenchymal transition and lens differentiation. Mol. Vis. 2006, 12, 422-440.

11. Border, W.A.; Noble, N.A.; Yamamoto, T.; Harper, J.R.; Yamaguchi, Y.; Pierschbacher, M.D.; Ruoslahti, E. Natural inhibitor of transforming growth factor-beta protects against scarring in experimental kidney disease. Nature 1992, 360, 361-364. [CrossRef]

12. Kubo, E.; Shibata, S.; Shibata, T.; Kiyokawa, E.; Sasaki, H.; Singh, D.P. FGF2 antagonizes aberrant TGFbeta regulation of tropomyosin: Role for posterior capsule opacity. J. Cell. Mol. Med. 2017, 21, 916-928. [CrossRef]

13. Mincione, G.; Esposito, D.L.; Di Marcantonio, M.C.; Piccirelli, A.; Cama, A.; Colletta, G. TGF-beta 1 modulation of IGF-I signaling pathway in rat thyroid epithelial cells. Exp. Cell Res. 2003, 287, 411-423. [CrossRef]

14. Seomun, Y.; Kim, J.; Lee, E.H.; Joo, C.K. Overexpression of matrix metalloproteinase-2 mediates phenotypic transformation of lens epithelial cells. Biochem. J. 2001, 358, 41-48. [CrossRef]

15. Chamberlain, C.G.; McAvoy, J.W. Induction of lens fibre differentiation by acidic and basic fibroblast growth factor (FGF). Growth Factors 1989, 1, 125-134. [CrossRef]

16. McAvoy, J.W.; Chamberlain, C.G. Fibroblast growth factor (FGF) induces different responses in lens epithelial cells depending on its concentration. Development 1989, 107, 221-228.

17. Nishi, O.; Nishi, K.; Fujiwara, T.; Shirasawa, E.; Ohmoto, Y. Effects of the cytokines on the proliferation of and collagen synthesis by human cataract lens epithelial cells. Br. J. Ophthalmol. 1996, 80, 63-68. [CrossRef]

18. Kubo, E.; Hasanova, N.; Fatma, N.; Sasaki, H.; Singh, D.P. Elevated tropomyosin expression is associated with epithelialmesenchymal transition of lens epithelial cells. J. Cell. Mol. Med. 2013, 17, 212-221. [CrossRef]

19. Bhargavan, B.; Chhunchha, B.; Fatma, N.; Kubo, E.; Kumar, A.; Singh, D.P. Epigenetic repression of LEDGF during UVB exposure by recruitment of SUV39H1 and HDAC1 to the Sp1-responsive elements within LEDGF promoter CpG island. Epigenetics 2013, 8, 268-280. [CrossRef]

20. Maniatis, T.; Fritsch, E.F.; Sambrook, J. Molecular Cloning. A Laboratory Manual; Cold Spring Harbor Laboratory: Cold Spring Harbor, NY, USA, 1982.

21. Fatma, N.; Kubo, E.; Sharma, P.; Beier, D.R.; Singh, D.P. Impaired homeostasis and phenotypic abnormalities in Prdx6-/-mice lens epithelial cells by reactive oxygen species: Increased expression and activation of TGFbeta. Cell Death Differ. 2005, 12, 734-750. [CrossRef]

22. Kubo, E.; Fatma, N.; Akagi, Y.; Beier, D.R.; Singh, S.P.; Singh, D.P. TAT-mediated PRDX6 protein transduction protects against eye lens epithelial cell death and delays lens opacity. Am. J. Physiol. Cell Physiol 2008, 294, C842-C855. [CrossRef]

23. Kubo, E.; Singh, D.P.; Fatma, N.; Shinohara, T.; Zelenka, P.; Reddy, V.N.; Chylack, L.T. Cellular distribution of lens epitheliumderived growth factor (LEDGF) in the rat eye: Loss of LEDGF from nuclei of differentiating cells. Histochem. Cell Biol. 2003, 119, 289-299. [CrossRef]

24. Zhao, H.; Yang, Y.; Rizo, C.M.; Overbeek, P.A.; Robinson, M.L. Insertion of a Pax6 consensus binding site into the alphaA-crystallin promoter acts as a lens epithelial cell enhancer in transgenic mice. Investig. Ophthalmol. Vis. Sci. 2004, 45, 1930-1939. [CrossRef]

25. Kubo, E.; Hasanova, N.; Sasaki, H.; Singh, D.P. Dynamic and differential regulation in the microRNA expression in the developing and mature cataractous rat lens. J. Cell. Mol. Med. 2013, 17, 1146-1159. [CrossRef]

26. Kubo, E.; Miyazawa, T.; Fatma, N.; Akagi, Y.; Singh, D.P. Development- and age-associated expression pattern of peroxiredoxin 6, and its regulation in murine ocular lens. Mech. Ageing Dev. 2006, 127, 249-256. [CrossRef]

27. Shibata, T.; Shibata, S.; Ishigaki, Y.; Kiyokawa, E.; Ikawa, M.; Singh, D.P.; Sasaki, H.; Kubo, E. Tropomyosin 2 heterozygous knockout in mice using CRISPR-Cas9 system displays the inhibition of injury-induced epithelial-mesenchymal transition, and lens opacity. Mech. Ageing Dev. 2018, 171, 24-30. [CrossRef]

28. General Assembly of the World Medical Association. World Medical Association Declaration of Helsinki: Ethical principles for medical research involving human subjects. J. Am. Coll. Dent. 2004, 15, 124-129.

29. Thylefors, B.; Chylack, L.T., Jr.; Konyama, K.; Sasaki, K.; Sperduto, R.; Taylor, H.R.; West, S.; The WHO Cataract Grading Group. A simplified cataract grading system. Ophthalmic Epidemiol. 2002, 9, 83-95. [CrossRef] 
30. Azuma, N.; Hara, T.; Hara, T. Extracellular matrix of opacified anterior capsule after endocapsular cataract surgery. Graefes Arch. Clin. Exp. Ophthalmol. 1998, 236, 531-536. [CrossRef]

31. Kubo, E.; Shibata, T.; Singh, D.P.; Sasaki, H. Roles of TGF beta and FGF Signals in the Lens: Tropomyosin Regulation for Posterior Capsule Opacity. Int. J. Mol. Sci. 2018, 19, 3093. [CrossRef]

32. Goldoni, S.; Humphries, A.; Nystrom, A.; Sattar, S.; Owens, R.T.; McQuillan, D.J.; Ireton, K.; Iozzo, R.V. Decorin is a novel antagonistic ligand of the Met receptor. J. Cell Biol. 2009, 185, 743-754. [CrossRef] [PubMed]

33. Schaefer, L.; Iozzo, R.V. Biological functions of the small leucine-rich proteoglycans: From genetics to signal transduction. J. Biol. Chem. 2008, 283, 21305-21309. [CrossRef] [PubMed]

34. Iozzo, R.V. Matrix proteoglycans: From molecular design to cellular function. Annu. Rev. Biochem. 1998, 67, 609-652. [CrossRef] [PubMed]

35. Grant, D.S.; Yenisey, C.; Rose, R.W.; Tootell, M.; Santra, M.; Iozzo, R.V. Decorin suppresses tumor cell-mediated angiogenesis. Oncogene 2002, 21, 4765-4777. [CrossRef] [PubMed]

36. Petit, A.M.; Rak, J.; Hung, M.C.; Rockwell, P.; Goldstein, N.; Fendly, B.; Kerbel, R.S. Neutralizing antibodies against epidermal growth factor and ErbB-2/neu receptor tyrosine kinases down-regulate vascular endothelial growth factor production by tumor cells in vitro and in vivo: Angiogenic implications for signal transduction therapy of solid tumors. Am. J. Pathol. 1997, 151, 1523-1530. [PubMed]

37. Penc, S.F.; Pomahac, B.; Winkler, T.; Dorschner, R.A.; Eriksson, E.; Herndon, M.; Gallo, R.L. Dermatan sulfate released after injury is a potent promoter of fibroblast growth factor-2 function. J. Biol. Chem. 1998, 273, 28116-28121. [CrossRef] [PubMed]

38. Lyon, M.; Deakin, J.A.; Rahmoune, H.; Fernig, D.G.; Nakamura, T.; Gallagher, J.T. Hepatocyte growth factor/scatter factor binds with high affinity to dermatan sulfate. J. Biol. Chem. 1998, 273, 271-278. [CrossRef]

39. Kurosaka, D.; Kato, K.; Nagamoto, T.; Negishi, K. Growth factors influence contractility and alpha-smooth muscle actin expression in bovine lens epithelial cells. Invest. Ophthalmol. Vis. Sci. 1995, 36, 1701-1708.

40. Meacock, W.R.; Spalton, D.J.; Stanford, M.R. Role of cytokines in the pathogenesis of posterior capsule opacification. Br. J. Ophthalmol. 2000, 84, 332-336. [CrossRef]

41. Grisanti, S.; Szurman, P.; Warga, M.; Kaczmarek, R.; Ziemssen, F.; Tatar, O.; Bartz-Schmidt, K.U. Decorin modulates wound healing in experimental glaucoma filtration surgery: A pilot study. Investig. Ophthalmol. Vis. Sci. 2005, 46, 191-196. [CrossRef]

42. Hill, L.J.; Mead, B.; Blanch, R.J.; Ahmed, Z.; De Cogan, F.; Morgan-Warren, P.J.; Mohamed, S.; Leadbeater, W.; Scott, R.A.; Berry, M.; et al. Decorin Reduces Intraocular Pressure and Retinal Ganglion Cell Loss in Rodents Through Fibrolysis of the Scarred Trabecular Meshwork. Invest. Ophthalmol. Vis. Sci. 2015, 56, 3743-3757. [CrossRef]

43. Vial, C.; Gutierrez, J.; Santander, C.; Cabrera, D.; Brandan, E. Decorin interacts with connective tissue growth factor (CTGF)/CCN2 by LRR12 inhibiting its biological activity. J. Biol. Chem. 2011, 286, 24242-24252. [CrossRef]

44. Davies, J.E.; Tang, X.; Denning, J.W.; Archibald, S.J.; Davies, S.J. Decorin suppresses neurocan, brevican, phosphacan and NG2 expression and promotes axon growth across adult rat spinal cord injuries. Eur. J. Neurosci. 2004, 19, 1226-1242. [CrossRef]

45. Ahmed, A.K.; Haylor, J.L.; El Nahas, A.M.; Johnson, T.S. Localization of matrix metalloproteinases and their inhibitors in experimental progressive kidney scarring. Kidney Int. 2007, 71, 755-763. [CrossRef]

46. Nassar, K.; Luke, J.; Luke, M.; Kamal, M.; Abd El-Nabi, E.; Soliman, M.; Rohrbach, M.; Grisanti, S. The novel use of decorin in prevention of the development of proliferative vitreoretinopathy (PVR). Graefes Arch. Clin. Exp. Ophthalmol. 2011, 249, 1649-1660. [CrossRef]

47. Isaka, Y.; Brees, D.K.; Ikegaya, K.; Kaneda, Y.; Imai, E.; Noble, N.A.; Border, W.A. Gene therapy by skeletal muscle expression of decorin prevents fibrotic disease in rat kidney. Nat. Med. 1996, 2, 418-423. [CrossRef]

48. Davies, J.E.; Tang, X.; Bournat, J.C.; Davies, S.J. Decorin promotes plasminogen/plasmin expression within acute spinal cord injuries and by adult microglia in vitro. J. Neurotrauma 2006, 23, 397-408. [CrossRef]

49. Fernandez, V.; Fragoso, M.A.; Billotte, C.; Lamar, P.; Orozco, M.A.; Dubovy, S.; Willcox, M.; Parel, J.M. Efficacy of various drugs in the prevention of posterior capsule opacification: Experimental study of rabbit eyes. J. Cataract Refract. Surg. 2004, 30, 2598-2605. [CrossRef]

50. D'Antin, J.C.; Barraquer, R.I.; Tresserra, F.; Michael, R. Prevention of posterior capsule opacification through intracapsular hydrogen peroxide or distilled water treatment in human donor tissue. Sci. Rep. 2018, 8, 12739. [CrossRef]

51. Boswell, B.A.; Korol, A.; West-Mays, J.A.; Musil, L.S. Dual function of TGFbeta in lens epithelial cell fate: Implications for secondary cataract. Mol. Biol. Cell 2017, 28, 907-921. [CrossRef]

52. Wertheimer, C.; Siedlecki, J.; Kook, D.; Mayer, W.J.; Wolf, A.; Klingenstein, A.; Kampik, A.; Eibl-Lindner, K. EGFR inhibitor Gefitinib attenuates posterior capsule opacification in vitro and in the ex vivo human capsular bag model. Graefes Arch. Clin. Exp. Ophthalmol. 2015, 253, 409-417. [CrossRef] [PubMed] 